\title{
PENGEMBANGAN SOFT SKILLS DALAM KURIKULUM UNTUK MENGHADAPI REVOLUSI INDUSTRI 4.0
}

\author{
Sri Siswati \\ Administrasi Kebijakan Kesehatan, Fakultas Kesehatan Masyarakat Universitas Andalas \\ Jalan Universitas Andalas, Limau Manis, Pauh, Padang - 25163 \\ e-mail: srisiswati@yahoo.co.id
}

\begin{abstract}
Abstrak
Revolusi industri 4.0 yang ditandai dengan persaingan yang kompetitif dan informasi yang pesat pada semua sektor, termasuk Sumber Daya Manusianya. Indonesia dituntut memiliki daya saing yang kuat agar mampu mensejajarkan diri dengan negara-negara lain. Kemajuan Teknologi Informasi dan Komunikasi dan era revolusi industri 4.0 wajib diimbangi dengan kurikulum pendidikan yang menunjang sehingga menghasilkan Sumber Daya Manusia (SDM) yang mempunyai kompetensi dan mampu bersaing. Kajian artikel ini bertujuan untuk mengetahui kemampuan yang harus dimiliki para generasi muda dalam rangka menghadapi revolusi industri 4.0. Artikel ini dibuat berdsarkan kajian kurikulum yang ada saat ini, dan kebutuhan kompetensi sumber daya manusia dengan peningkatan kemampuan pendidikan berkarakter. Dari kajian ini diperoleh bahwa di zaman era Revolusi Industri, diperlukan kemampuan problem solving yang baik, pintar berkomunikasi dan melobi, mempunyai soft skills serta penyesuaian diri., Proses pembelajaran dititikberatkan pada soft skills. Program Student Center Learning diimplementasikan dalam akhlak, moral, etik, serta inovasi pengetahuan secara terus menerus.
\end{abstract}

Kata Kunci: soft skills, kurikulum, Revolution Industri 4.0.

\begin{abstract}
The industrial revolution 4.0 was marked by intense competition and rapid information flow in all sectors, including its Human Resources. Indonesia is demanded to have strong competitiveness to be able to align itself with other countries. The progress of Information and Communication Technology and the era of the industrial revolution 4.0 must be balanced with supporting educational curricula to produce Human Resources (HR) who have the competence and can compete. The review of this article aims to determine the abilities that young people must possess to face the industrial revolution 4.0. This article is based on the current curriculum study, and the need for competency in human resources by increasing the ability of character education. From this study, it was found that in the era of the Industrial Revolution, good problem-solving skills, good communication, and lobbying skills, soft skills and adaptation was needed. The learning process focused on soft skills. The Student Center Learning Program is implemented in character, morals, ethics, and continuous knowledge innovation.
\end{abstract}

Keywords: soft skills, curriculum, Industrial Revolution 4.0.

\section{PENDAHULUAN}

Menghadapi revolusi industri 4.0 yang ditandai dengan persaingan yang kompetitif dan informasi yang pesat pada semua sektor, Indonesia diharuskan memiliki daya saing yang kuat agar mampu mensejajarkan diri dengan negaranegara lain. Kemajuan teknologi informasi dan komunikasi (TIK) dan era revolusi 
industri 4.0 wajib diimbangi dengan soft skills (Rusydan, 2012). Kurikulum pendidikan harus dirancang untuk menghasilkan sumber daya manusia (SDM) yang mampu dan siap (Ariyanti, 2018). Kemampuan yang harus dimiliki para generasi muda dalam rangka menghadapi revolusi industri 4.0 adalah kemampuan berpikir kritis, kreatif, inovatif, berkomunikasi, bekerja sama, dan percaya diri (Tosepu, 2019). Meningkatkan kualitas dan kuantitas inovasi di era revolusi industri 4.0, perguruan tinggi perlu melakukan reorientasi kurikulum agar tetap relevan dengan perkembangan zaman (Rosmiaty, 2018).

Kebijakan kurikulum harus mengelaborasi kemampuan peserta didik pada dimensi pedagogik, kecakapan hidup, kemampuan hidup bersama (kolaborasi), berpikir kritis, dan kreatif. Peserta didik harus mempunyai soft skills, transversal skills, keterampilan hidup, dan keterampilan yang secara kasat tidak terkait dengan bidang pekerjaan dan akademis tertentu saja (Universitas Islam Indonesia, 2018). Kurikulum harus memperhatikan perkembangan pendidikan berbasis vokasional dengan ragam keterampilan yang tidak sekadar mengedepankan konsep link and match antara perguruan tinggi dengan dunia industri, tetapi juga menekankan kapasitas lulusan yang lincah, adaptif, dan sensitif terhadap perubahan lingkungan industri dan ekonomi.

Implementasi kurikulum di perguruan tinggi mengalami degradasi yang keluar konteks dan tidak lagi berorientasi pada pencapaian kemampuan peserta didik pada pemahaman ilmu dalam konteks praktik hidup dan keseharian (kompetensi keterampilan hidup), namun hanya berkisar pada target pencapaian kompetensi peserta didik yang digambarkan pada nilai-nilai akademik saja (WE Online, 2019). Untuk bisa beradaptasi dengan perubahan yang diakibatkan oleh revolusi industri 4.0, seseorang harus memiliki kemampuan yang tidak akan bisa dilakukan oleh mesin, seperti kemampuan untuk memecahkan masalah atau kreativitas.

Soft skills di era revolusi industri 4.0. yang harus dimiliki oleh seseorang, terutama menghadapi persaingan kerja pada tahun 2020 yaitu pemecahan masalah yang kompleks, berpikir kritis, kreativitas, manajemen manusia, berkoordinasi dengan orang lain, kecerdasan emosional, penilaian dan pengambilan keputusan, 
berorientasi servis, negosiasi, fleksibel, dan kemampuan kognitif (Universitas Prasetiya Mulya, 2019). Lebih dari setengah skills tersebut mengutamakan soft skills. Artinya, soft skills menjadi salah satu faktor paling penting untuk dimiliki para seseorang di masa depan, seperti kemampuan berkomunikasi dan bekerja sama dengan orang lain, memecahkan masalah, serta aspek kecerdasan emosional lainnya.

Perguruan tinggi harus menerapkan pendidikan yang berimbang antara hard skills dan soft skills agar menghasilkan lulusan yang kompeten di bidangnya,. Mahasiswa dilibatkan dalam proses belajar dan kehidupan kampus secara terstruktur dan terintegrasi. Mahasiswa dilatih untuk bisa bersikap kritis. Melalui sistem pembelajaran yang juga menekankan pengembangan soft skills, selain keterampilan teknis, lulusan perguruan tinggi akan bisa lebih mampu beradaptasi secara cepat terhadap perubahan serta memiliki bekal yang mumpuni untuk menghadapi masa depan dan pengembangan kariernya dalam menghadapi perkembangan yang terjadi pada era revolusi industri 4.0.

\section{Revolusi Industri 4.0 dan Distruption Era}

Kehidupan manusia di tahun 2000 memasuki era baru yang disebut dengan Era Revolusi Industri 4.0 (four point zero). Ciri utama era revolusi industri 4.0 adalah semakin berkurangnya peran manusia secara fisik dalam berbagai aktivitas sehari-hari dan produksi (Wafi, 2019). Satu yang paling dihargai pada diri manusia adalah creativity. Contoh wujud era revolusi industri 4.0 saat melakukan e-parking di pusat perbelanjaan, mesin berkomunikasi dengan mesin. Tinggal tekan tombol, lalu keluar karcis dan selanjutnya portal dibuka. Tidak ada interaksi dengan manusia. Wongso (2019) mengungkapkan bahwa untuk bisa bertahan di era revolusi industri 4.0, manusia harus memiliki tiga literasi utama yaitu: (1) Literasi data (data literacy); (2) Literasi teknologi (technology literacy); dan (3) Literasi manusia (human literacy).

Jenis literasi manuasia terkait dengan keterampilan memimpin, kemampuan bekerja dalam tim, serta keterampilan memahami budaya orang lain dan menjalin hubungan dengan manusia lintas budaya. Untuk menjalin hubungan tersebut, 
manusia terlebih dahulu melakukan kontak dan komunikasi. Toffler (2011) juga telah menguraikan perkembangan kehidupan manusia mulai abad 21 dengan istilah masyakat gelombang ketiga (the third wave society) dan masyarakat informasi (information society). Perubahan dunia yang demikian cepat tentunya harus diiringi oleh praktik pendidikan yang relevan dengan kebutuhan terhadap perubahan tersebut. Pendidikan yang relevan dengan perubahan zaman adalah pendidikan yang mengutamakan terbentuknya life skills dan soft skills serta hard skills.

\section{Tantangan dan Peluang bagi Dunia Pendidikan}

Pendidikan adalah sektor yang dianggap paling bertanggung jawab untuk mempersiapkan generasi muda menghadapi masa depannya, bagaimanapun bentuknya. Pada masa yang akan datang, tantangan hidup tidak akan mudah, bahkan semakin susah. Susah dalam artian penuh tantangan dan persaingan. Dalam kaitannya dengan perubahan kehidupan global yang semakin cepat, diperlukan langkah-langkah antisipatif oleh pemerintah melalui pengembangan kurikulum yang didasari oleh kondisi-kondisi internal maupun eksternal. Persiapan untuk sukses di era revolusi industri 4.0 dan era disruptif tersebut telah dilaksanakan oleh pemerintah melalui jalur pendidikan, seperti terdapat dalam kurikulum (Malingkas, 2019). Contoh di perguruan tinggi, setiap lulusannya harus memiliki minimal empat kompetensi, yaitu academic knowledge, skills of thinking, management skills, serta communication skills.

Keempat kompetensi tersebut menyatu dalam diri seorang lulusan perguruan tinggi. Jika tidak lengkap, maka akan berpengaruh terhadap kualitas diri lulusan tersebut. Demikian juga dengan kurikulum pada jenjang pendidikan dasar (SD dan SMP) dan pendidikan menengah (SMA/SMK). Pemberlakuan Kurikulum 2013 dengan ciri utamanya scientific approach dan pengalaman belajar 5M, terdapat ruang yang cukup untuk mengembangkan keterampilan berkomunikasi dalam pembelajaran. Dalam learning experiences dengan pola lima " $M$ " terdapat " $M$ " mengkomunikasikan yang berarti siswa dimotivasi dan didorong untuk aktif menyampaikan pertanyaan, pandangan serta ide-ide terkait 
permasalahan yang sedang dicarikan solusinya dalam pembelajaran. Dalam standar proses pelaksanaan pembelajaran Kurikulum 2013 dijelaskan bahwa pembelajaran harus bersifat interaktif. Hal tesebut berati bahwa terjalin komunikasi yang efektif dalam pembelajaran.

Terlihat bahwa di masa datang, apapun nama eranya akan sangat membutuhkan manusia yang memiliki keterampilan komprehensif, baik hard skills, soft skills, dan life skills yang termasuk didalamnya adalah keterampilan berkomunikasi dan public speaking (Yahya, 2018). Tugas-tugas yang memerlukan keahlian berpikir (expert thinking) dan komunikasi yang kompleks (complex communication) menjadi sangat penting bagi setiap orang di masa depan (Levy and Murnane, 2004).

Satu lagi yang perlu menjadi perhatian dunia pendidikan adalah pendapat Wagner (2008) yang mengungkapka ada tujuh keterampilan abad 21 yang harus dimiliki (The Survival Skills for 21 Century), yaitu: (1) Critical thinking and problem solving; (2) Collaboration; (3) Agility and adaptability; (4) Initiative and enterpreneurialism; (5) Effective oral and written communication; (6) Accessing and analyzing information; dan (7) Curiosity and imagination. Tantangan revolusi industri 4.0 sebagai berikut: (1) Masalah keamanan teknologi informasi; (2) Keandalan dan stabilitas mesin produksi; (3) Kurangnya keterampilan yang memadai; (4) Keengganan untuk berubah oleh para pemangku kepentingan; dan (5) Hilangnya banyak pekerjaan karena berubah menjadi otomatisasi.

Muatan pembelajaran abad 21 harus selalu menyesuaikan dengan perubahan, termasuk di era revolusi industri 4.0. Muatan pembelajaran diharapkan mampu memenuhi keterampilan abad 21 (Kusumah, 2019) . Keterampilan abad 21 (21 century skills) tersebut meliputi: (1) Pembelajaran dan keterampilan inovasi, meliputi penguasan pengetahuan dan keterampilan yang beraneka ragam, pembelajaran dan inovasi, berpikir kritis dan penyelesaian masalah, komunikasi dan kolaborasi, serta kreativitas dan inovasi; (2) Keterampilan literasi digital, meliputi literasi informasi, literasi media, dan literasi teknologi komputer; (3) Karier dan kecakapan hidup, meliputi fleksibilitas dan adaptabilitas, inisiatif, 
interaksi sosial dan budaya, produktivitas dan akuntabilitas, serta kepemimpinan dan tanggung jawab (Trilling and Fadel, 2009).

\section{Urgensi Public Speaking sebagai Atribut Soft Skills}

Keterampilan berkomunikasi di masa mendatang merupakan salah satu kunci sukses hidup dan bertahan di era revolusi industri 4.0 dan disruption era. Nofrion (2018) menjelaskan bahwa keterampilan public speaking sudah menjadi kebutuhan semua orang, siapapun, dan apapun jabatan dan posisi.

Beberapa arti penting public speaking yaitu: (1) Kemampuan public speaking adalah keharusan hampir semua profesi (guru, dosen, manajer, pendakwah, instruktur, narasumber, penyiar, dan pembawa acara); (2) Melalui public speaking seseorang bisa menyampaikan ide/pemikiran kepada orang banyak secara efektif dan respektif; (3) Melalui public speaking, "transfer of knowledge" dapat dilakukan dengan lebih bermakna dan memicu terjadinya perubahan komprehensif pada diri pendengar, tidak hanya aspek pengetahuan saja tapi juga aspek afektif dan psikomotori; (4) Kemampuan dalam public speaking akan memengaruhi tingkat perkembangan pribadi dan lingkungan sosial; (5) Dengan menguasai public speaking seseorang akan memiliki kesempatan yang luas untuk mengaktualisasikan segala potensi di hadapan orang lain; (6) Public speaking adalah sarana untuk pengembangan dan pemberdayaan diri secara berkelanjutan; (7) Kemampuan public speaking mendukung kepemimpinan (leadership); (8) Kemampuan public speaking menumbuhkan kepercayaan diri (self confident); (9) Kemampuan public speaking berkontribusi dalam meningkatkan prestasi; (10) Kemampuan public speaking akan mendukung dan mempermudah sampainya suatu informasi, pesan, materi, pelajaran atau dakwah dari komunikator kepada komunikan secara lebih efektif dan efisien.

Lucas (2015) menjelaskan bahwa keahlian dalam percakapan adalah bagian penting dalam public speaking. Seseorang yang terbiasa mahir dalam melakukan percakapan dengan orang lain akan memiliki kemampuan dalam hal public speaking karena orang tersebut telah terbiasa untuk: (1) Mengorganisasi pikiran sesuai logika; (2) Menyampaian pesan sesuai dengan lawan bicara. Orang yang 
mahir dalam percakapan adalah orang yang piawai dalam menjalin tautan antara topik pembicaraan; (3) Menyampaikan cerita atau informasi untuk dampak yang optimal; dan (4) Beradaptasi dengan feedback yang berasal dari lawan bicara.

Beragam terobosan metode dengan menstimulus kemampuan peserta didik untuk berpikir kritis dalam beragam konteks hidup yang nanti akan dihadapinya, seperti: problem-based learning; inquiry-based learning; pendekatan pembelajaran science, technology, egineering, arts, dan mathematics (STEAM); serta beragam pendekatan pembelajaran lainnya. Pembelajaran tidak sekadar berfokus pada pola-pola lama dan monoton serta pembelajaran yang minim kreativitas. Mahasiswa tidak berproses dalam mendengar dosen mengajar, mencatat, dan menghafalnya untuk ujian. jika terjadi demikian, maka ilmu tersebut terlupakan secara cepat. Mahasiswa karus kreatif dan tidak hanya mengetahui ilmunya, tetapi merasakan dan mengembangkan serta mencari inovasi baru dari ilmu tersebut.

Mahasiswa haruas rajin membaca, mengakses pengembangan ilmu tersebut dengan sistem online yang tidak berbatas wilayah. Mahasiswa melakukan temuan dan inovasi baru dengan pertimbangan harga lebih murah, lebih menguntungkan, dan menemukan hal-hal baru yang lebih bermanfaat. Mahasiswa membutuhkan kemampuan soft skills yang berimbang dengan hard skills. Misalnya dalam moral, tidak knowing moral saja, tetapi filling moral dan implementation moral. Perguruan tinggi harus melatih dan mengajarkan soft skills yang memang dibutuhkan oleh dunia kerja yang bersinergi dengan kebutuhan dunia usaha dan industri 4.0.

\section{Atribut Soft Skills Lainnya}

Hasil survei National Association of Colleges and Employers di Amerika Serikat pada tahun 2002 (disurvei dari 457 pimpinan), ternyata indeks prestasi kumulatif (IPK) bukanlah hal yang dianggap penting di dalam dunia kerja, melainkan yang lebih penting adalah soft skills. Soft skills adalah keterampilan seseorang dalam berhubungan dengan orang lain (termasuk dengan dirinya sendiri). Soft skills yang dimaksud yaitu: kemampuan komunikasi; kejujuran dan 
kerja sama; motivasi; kemampuan beradaptasi; serta kompetensi interpersonal lainnya dengan orientasi nilai yang menjunjung kinerja yang efektif.

Atribut soft skills lainnya meliputi nilai yang dianut, motivasi, perilaku, kebiasaan, karakter, dan sikap. Atribut soft skills tersebut dimiliki oleh setiap orang dengan kadar yang berbeda-beda yang dipengaruhi oleh kebiasaan thinking skills, berkata, bertindak, dan bersikap. Atribut tersebut diurut berdasarkan prioritas kepentingan di dunia kerja, yaitu: (1) Inisiatif; (2) Integritas; (3) Berpikir kritis; (4) Kemauan belajar; (5) Komitmen; (6) Motivasi; (7) Bersemangat; (8) Dapat diandalkan; (9) Komunikasi lisan; (10) Kreatif; (11) Kemampuan analitis; (12) Dapat mengatasi stres; (13) Manajemen diri; (14) Kemampuan menyelesaikan masalah; (15) Dapat meringkas; (16) Kooperatif (17) Fleksibel; (18) Bekerja dalam tim; (19) Mandiri; (20) Mendengarkan; (21) Tangguh; (22) Beragumentasi logis; dan (23) Manajemen waktu.

Sejumlah soft skills tersebut hendaknya diimplementasikan dalam proses pembelajaran student center learning. Mahasiswa dapat dimotivasi dengan metode pembelajaran yang tumbuh dan berkembang dari diri sendiri. Mahasiswa diberikan stimulus dalam proses pembelajaran berkelompok, pengaturan tugas masing-masing, dan menyampaikan hasil pembelajaran yang diperoleh. Kelompok lain dapat memberikan klarifikasi, pertanyaan, saran serta masukan dari hasil kelompok lainnya. Proses tersebut dapat dibuat menjadi lebih strategik dengan atmosfir yang menarik minat mahasiswa untuk belajar. Dosen diakhir pembelajaran memberikan masukan, meluruskan, dan memberikan nilai yang membangun minat mahasiswa.

Indikator perilaku dalam proses pembelajaran seperti akhlak dan moral, mahasiswa diajak menginstropeksi diri secara masing-masing, apakah hal tersebut sudah dilaksanakan atau belum dilaksanakan. Bagaimana mahasiswa berkomunikasi dengan dosen secara langsung, melalui aplikasi online dan sebagainya. Dari waktu ke waktu dosen dapat memberikan masukan yang dirasakan dan didiskusikan bersama-sama. Secara berangsur, kemajuan capaian pembelajaran akan disampaikan. Dosen juga harus berbesar hati jika dalam pembelajaran mendapat masukan dari mahasiswa. Diakhir proses pembelajaran, 
dosen dapat memberikan ujian dan mengukur capaian proses pembelajaran yang ditetapkan. Diharapkan capaian pembelajaran mengalami peningkatan terus menerus. Dalam proses pembuatan soal ujianpun, bisa dibentuk tim independen untuk memvalidasi soal apakah sesuai dengan yang diajarkan dan capaian pembelajaran dan bagian apa yang akan diukur.

\section{SIMPULAN}

Impelemntasi kurikulum hanya berorientasi pada target pencapaian kompetensi peserta didik yang digambarkan pada nilai-nilai akademik. Menstimulus kemampuan peserta didik melalui beragam terobosan metode belajar kontekstual yang mendorong peserta didik berpikir kritis dalam beragam konteks hidup yang nanti dihadapi, seperti problem-based learning; inquiry-based learning; pendekatan pembelajaran science, technology, engineering, arts, dan mathematics (STEAM); dan ragam pendekatan pembelajaran lainnya. Sehingga tidak sekadar berfokus pada pola-pola lama dan monoton pada pembelajaran yang minim kreativitas. Perguruan tinggi harus melatih dan mengajarkan soft skills yang dibutuhkan sehingga bersinergi dengan kebutuhan dunia usaha dan industri 4.0. Proses pembelajaran dilaksanakan dengan proses student center learning dengan pencapaian indikator perilaku.

\section{DAFTAR PUSTAKA}

Ariyanti, H. 2018. Hadapi Revolusi Industri 4.0, Mendikbud akan Rancang Ulang Kurikulum dalam https://www.merdeka.com/peristiwa/hadapi-revolusiindustri-40-mendikbud-akan-rancang-ulang-kurikulum.html Diakses 5 Maret 2019.

Kusumah, W. 2019. Menyiapkan Guru dan Dosen di Era Revolusi Industri 4.0 dalam https://www.kompasiana.com/wijayalabs/5dd36340d541df29bf6153 c2/menyiapkan-guru-dan-dosen-di-era-revolusi-induatri-4-0 Diakses 30 November 2019.

Levy, F. \& Murnane, R. J. 2004. The New Division of Labor. Princeton: Princeton University Press.

Lucas, S. 2015. The Art of Public Speaking dalam https://www.mheducation. com/highered/product/art Diakses 30 November 2019.

Malingkas, J. 2019. Membangun Etos Kerja dalam Era Revolusi Industri 4.0 dalam https://www.kompasiana.com/johanisalbertmalingkaspacaran/ 
5dc9115bd541df66b54869a2/membangun-etos-kerja-dalam-era-revolusiindustri-4-0 Diakses 30 November 2019.

Nofrion. 2018. Pentingnya Public Speaking bagi Dosen, Guru, dan Mahasiswa. https://www.researchgate.net/publication/328515194 Diakses 18 Oktober 2019.

Rosmiaty, A. 2018. Implementasi Pengembangan Kurikulum. Makassar: Fakultas Tarbiyah dan Keguruan Alauddin Makassar.

Rusydan. 2012. Mengintegrasikan Soft Skills dalam Pembelajaran Interaktif dalam https://adoc.tips/rusydan-dosen-fkip-unisla-lamonggan.html Diakses 6 Maret 2019.

Tosepu, Y. A. 2019. Skills yang Harus Dimiliki Lulusan Perguruan Tinggi di Era Industri 4.0 dalam https://www.academia.edu/38123187/SKILLS_yang_ Harus_Dimiliki_Lulusan_Perguruan_Tinggi_di_Era_Industri_4.0 Diakses 5 Maret 2019.

Trilling, B. \& Fadel, C. 2009. $21^{\text {st }}$ Century Skills Learning for Life in Our Times. San Francisco: CA John Wiley \& Sons.

Universitas Islam Indonesia. 2018. Hadapi Revolusi Industri 4.0 Perlu Penyesuaian Kurikulum dalam https://www.uii.ac.id/perlu-penyesuaiankurikulum-hadapi-revolusi-industri-4-0/ Diakses 6 Maret 2019.

Universitas Prasetiya Mulya. 2019. Metode Pembelajaran Pendidikan dalam Menghadapi Revolusi Industri 4.0 dalam http://pmbs.ac.id/news/Metode_ Pembelajaran_Pendidikan_Dalam_Menghadapi_Revolusi_Industri_4.0 Diakses 30 November 2019.

Wafi, A. Y. 2019. Mengenal Lebih Dalam Apa Itu Revolusi Industri 4.0 dalam https://www.kompasiana.com/wafiahmad/5dce6752d541df3e090b6772/men genal-lebih-dalam-apa-itu-revolusi-industri-4-0 Diakses 30 November 2019.

Wagner, T. 2008. The Global Achievment Gap (The Survival Skills for 21 Century). USA: World Press.

WE Online. 2019. Agar Tak Ketinggalan Zaman Kurikulum Industri 4.0 Wajib Diterapkan dalam https://www.wartaekonomi.co.id/read/agar-takketinggalan-zaman-kurikulum-industri-40-wajib-diterapkan.html Diakses 6 Maret 2019.

Wongso, J. 2019. "Senjata” Indonesia dalam Menghadapi Revolusi Industri 4.0 dalam https://www.kompasiana.com/jonathanwongso2230/5dd1426bd541 df15a87c8e83/senjata-indonesia-dalam-menghadapi-revolusi-industri-4-0 Diakses 30 November 2019.

Yahya, M. 2018. Era Industri 4.0: Perubahan Dunia dan Urgensi Keterampilan Berkomunikasi/Public Speaking: Tantangan dan Peluang Perkembangan Pendidikan Kejuruan Indonesia. Makassar: Universitas Negeri Makasar. 